\title{
Interaction between mevalonate pathway and retinoic acid-induced differentiation
}

\author{
Naima Gueddari-Pouzols, ${ }^{1}$ Patrick Duriez, ${ }^{2}$ Christine Chomienne, ${ }^{3}$ \\ Aurélie Trussardi, ${ }^{1}$ and Jean Claude Jardillier ${ }^{{ }^{*}}$ \\ ${ }^{1}$ Laboratoire de Biochimie, EA 2063, IFR 53 Biomolécules, UFR de Pharmacie, 51, rue Cognacq-jay, 51096 Reims Cedex, France \\ ${ }^{2}$ Département de Recherche sur les Lipoproteines et l'Athérosclérose et U. 325 INSERM. Institut Pasteur, 59019 Lille, France \\ ${ }^{3}$ Laboratoire de Biologie Cellulaire Hématopoiétique, Hôpital Saint Louis, 1, Avenue Claude Vellefaux 75010 Paris, France
}

\begin{abstract}
All trans retinoic acid (ATRA) is a potent inducer of differentiation of HL-60 cell line. The pretreatment of the cells by compactin, a competitive inhibitor of 3-hydroxy-3-methylglutaryl (HMG) CoA reductase, during 24 hours, enhances the ATRA-induced cell differentiation. At $50 \mathrm{nM}$, the percentage of cell differentiation is $34.9 \% \pm 2$ and $73 \% \pm 2.96$ in the control and compactin-treated cells, respectively. The removal of compactin boosts the level of HMG-CoA reductase and therefore the biosynthesis of sterol and nonsterol isoprenoid compounds. The participation of sterol and nonsterol pathway was then investigated. The supply of an excess of cholesterol (up to $80 \mu \mathrm{g} / \mathrm{ml}$ of LDL) leads to a significant decrease of cell differentiation by ATRA from $78 \% \pm 0.1$ to $54 \% \pm 2.8$. A concomitant decrease of cell growth $(51 \% \pm 6.4)$ was observed. The pretreatment of cells by the geranylgeranyltransferase inhibitor (GGTI-298) has no effect on the cell differentiation process. By contrast, the farnesyltransferase inhibitors (FTI-II and FTI-277) completely abolish the ATRA-induced differentiation, thus confirming the involvement of farnesylated proteins in the differentiation mechanism.
\end{abstract}

\section{INTRODUCTION}

The retinoids play an important role in regulating a broad range of biological processes such as growth differentiation and development in a variety of cell types and tissues [1].

All trans retinoic acid (ATRA) exerts a potent differentiating action on human myelogenous leukemia HL-60 cell line and primary bone marrow cultures from patients with acute myelogenous leukemia (AML) [2,3]. One mechanism for the differentiating activity of ATRA in cells involves the RA nuclear receptors (RARs and RXR) [4], which have specific high-affinity binding sites for ATRA and some of its metabolites [5-7]. Other mechanisms may also be involved in RA-induced differentiation including retinoic acid acylation $[8,9]$.

A potent differentiating action of ATRA on leukemic cell line is accompanied by a marked cell growth inhibition, as evidenced by an increase of cells in $\mathrm{G}_{0}$ and a reduction of cells in $S$ phase [10]. However, until now, no clear evidence has been given to prove if both processes are independent or closely related. Our work focused on a possible common pathway based on mevalonate (MVA) metabolism.

Proliferation of cells is known to require at least 2 products synthesized from mevalonate: cholesterol and nonsterol isoprenoid derivatives, including farnesylated proteins especially those of ras family [11].

HMG-CoA reductase functions as the rate-limiting enzyme of the MVA pathway. It is highly regulated by a negative feedback mechanism. Indeed, the sterols repress transcription of the HMG-CoA reductase gene through a short sequence in the $5^{\prime}$ flanking region of the gene designated SRE-1 [12-14]. Nonsterol and sterol compounds control HMG-CoA reductase translation [15] and degradation rate $[16,17]$.

Mevalonate homeostasis is achieved through (i) sterolmediated feedback repression of the genes for HMG-CoA synthetase, HMG-CoA reductase, and the LDL receptor and (ii) posttranscriptional regulation of $\mathrm{HMG}-\mathrm{CoA}$ reductase [11].

The studies have identified a number of proteins with mevalonate-derived prenyl groups attached post-translationally $[18,19]$. Growth-regulating p 21 ras proteins encoded by ras protooncogenes and oncogenes are covalently attached to farnesyl residues which anchor them to the cell membrane.

In the search for MVA-derived compounds involved in growth control, much attention has been aimed at prenylated proteins [20]. Among them, Ras proteins have attracted special interest [21]. Indeed, p21ras proteins are involved in cell growth, and oncologically mutated forms of ras are found in a wide variety of human tumors $[18,22,23]$. Interestingly, Prendergast et al. [24] reported that inhibition of ras farnesylation with farnesyltransferase inhibitors leads to transformed phenotype reversion. However, these authors suggested that other prenylated proteins than Ras might be implicated in this mechanism.

Ras proteins are processed through a series of reactions that result in either farnesylation or geranylgeranylation at a cysteine residue at the fourth amino acid position from the carboxyl-terminal end [25].

The maturation of Ras proteins, heterodemic G proteins 
( $y$ subunit), nuclear lamins ( $\mathrm{A}$ and $\mathrm{B}$, and rhodopsin kinase, among others, requires their covalent attachment to $C_{15}$ (farnesyl) or $\mathrm{C}_{20}$ (geranylgeranyl) isoprenoids derived from mevalonate $[11,26,27]$. Isoprenylation-dependent membrane anchorage and subcellular localization of Ras protein is often required for their maturation and function[26-29].

The farnesylated proteins are necessary for cell growth $[18,19]$. On the other hand, induction of differentiation is well known to parallel a decrease of cell growth [10]. Here, we put in evidence that nonsterol compounds, derived from mevalonate pathway, could be a common key element involved in these two processes.

\section{MATERIALS AND METHODS}

\section{Cell culture and reagents}

HL-60 promyelocytic leukemic cells (American Type Culture collection, Rockville, MD) were grown in RPMI 1640 (GIBCO, France) supplemented with $15 \%$ heat inactivated fetal calf serum (GIBCO, France) and $2 \mathrm{mM}$ L-glutamine in a humidified atmosphere of $95 \%$ air, $5 \% \mathrm{CO}_{2}$. ATRA, from Hoffman-La Roche, France, was dissolved in dimethylsulfoxide (DMSO) at an initial stock concentration of $0.01 \mathrm{M}$ and stored at $-20^{\circ} \mathrm{C}$. At the time of analysis all samples were allowed to thaw in the dark at room temperature and diluted at the appropriate concentration in RPMI 1640 medium. In all cell cultures, the concentration of DMSO never exceeded $0.01 \%$. Compactin was obtained from Sigma and Farnesyltransferase inhibitor II from Calbiochem. Farnesyltransferase inhibitor 277 (FTI-277) and geranylgeranyltransferase inhibitor 298 (GGTI-298) were kind gifts from Said M. Sebti and Michelle A. Blaskovich (University of South Florida, H. Lee Moffitt Cancer Center \& Research Institute).

\section{Low-density lipoprotein (LDL) preparation}

Human LDL was prepared by ultracentrifugation using a Beckman TL 100 ultracentrifuge and a Beckman TL 100.2 fixed angle rotor [30].

\section{Induction of cell differentiation}

HL-60 cells were suspended in growth medium at $10 \times$ $10^{4}$ cells $/ \mathrm{ml}$ in the presence or absence of the indicated agent. The cell viability was assessed by trypan blue exclusion test. Differentiation was estimated by NBT reduction as previously described [31]. A minimum of 300 cells was counted and the percentage of differentiation (i.e., percentage of NBT positive cells) was calculated.

\section{Western blotting}

Cells were lysed with $2 \times$ Laemmli sample buffer. Samples $\left(10^{6}\right.$ cells/100 $\left.\mu \mathrm{l}\right)$ were boiled, sheared, and clarified by centrifugation in a microcentrifuge prior to storage at $-20^{\circ} \mathrm{C}$. Samples were separated on a $12.5 \%$ SDS polyacrylamide gel and electrophoretically transferred to nitrocellulose membrane. Membrane was blocked for 2 hours in TBS $(50 \mathrm{mM}$ Tris, $150 \mathrm{mM} \mathrm{NaCl}, \mathrm{pH} 7.5$ ) containing $0.1 \%$ Tween 20 (TBST) and 5\% powdered milk before antibody addition. Membrane was probed with monoclonal antibody directed

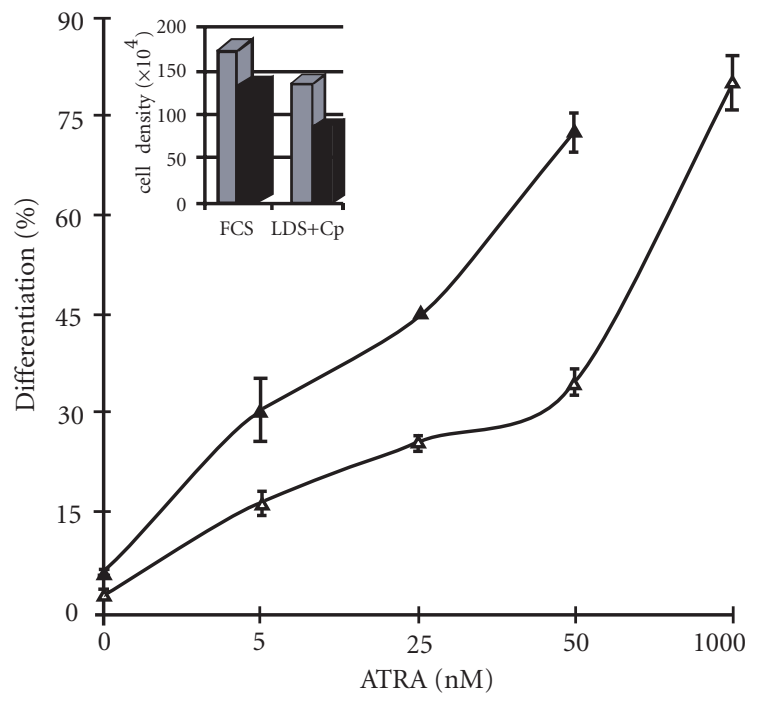

Figure 1: Effect of ATRA on HL-60 cell differentiation. HL-60 cells were incubated for 24 hours in foetal calf lipoprotein deprived serum (LDS medium) supplemented with compactin $(2 \mu \mathrm{M})$. Then, they were washed in phosphate buffered saline and cultured during 5 days in LDS medium containing increasing concentrations of ATRA $(\boldsymbol{\Lambda})$. The control cells were cultured during 5 days in FCS medium containing increasing concentrations of ATRA $(\triangle)$. At day 5 , cell differentiation was determined by NBT reduction and viable cell number as determined by Trypan blue exclusion. Insert: Effect on cell growth.

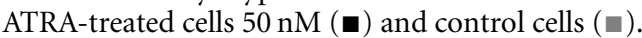

against $H$-ras, or with monoclonal antibody directed against $K$-ras or with polyclonal antibody directed against $N$-ras, all from Tebu-Santa Cruz, France. Detection was performed with ECL chemiluminescence system (Amersham).

\section{RESULTS}

\section{Effect of ATRA on differentiation of compactin-HL-60 treated cells}

The presence of compactin and cholesterol-deprived medium (LDS) had no effect on the basal differentiation activity of HL-60 cells. The treatment of HL-60 cells with ATRA induced a gradual increase of differentiated cells. When endogenous cholesterol synthesis was inhibited, in a first step for 24 hours by incubation in LDS containing compactin $(2 \mu \mathrm{M})$, then the removal of compactin induced an increase of the sterol and nonsterol pathways, a possible consequence of the overexpression of HMG-CoA reductase, ATRA induced cell differentiation but the effect was more pronounced in the cells temporarily treated with compactin. At $50 \mathrm{nM}$, ATRA induced, respectively, $34.9 \% \pm 2$ and $73 \% \pm 2.96$ of cell differentiation (Figure 1), in the control and compactintreated cells, whereas $1000 \mathrm{nM}$ was required to obtain $80 \% \pm 4$ in control cells.

Furthermore, at $50 \mathrm{nM}$ of ATRA, a strong increase of growth inhibition was observed in the differentiated compactin-treated cells compared with control cells $(80.5 \pm 5$ versus $132.5 \pm 30$ ) (Figure 1). 


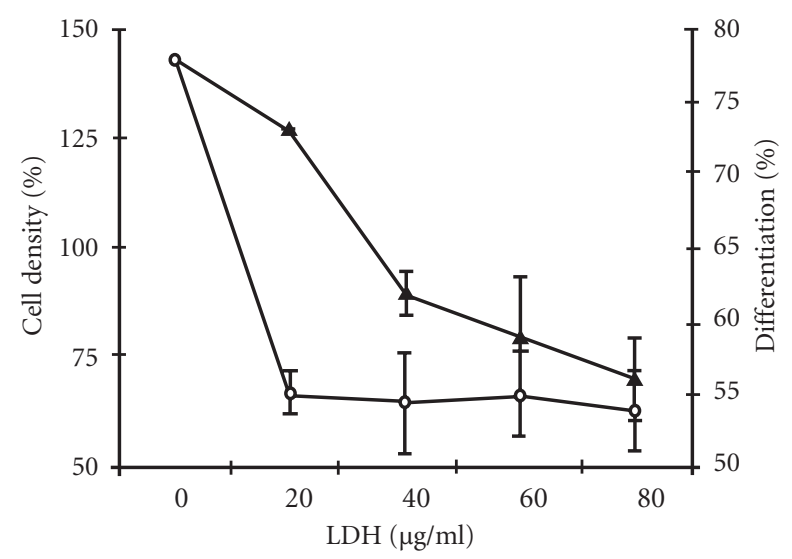

FIGURE 2: Effect of higher low-density lipoprotein concentrations on growth and differentiation of HL- 60 cells by ATRA. HL-60 cells were incubated during 5 days with $1 \mu \mathrm{M}$ ATRA and increasing concentrations of LDL. Differentiation as determined by NBT reduction ( 0 ) and viable cell number as determined by Trypan blue exclusion $(\boldsymbol{\Lambda})$.

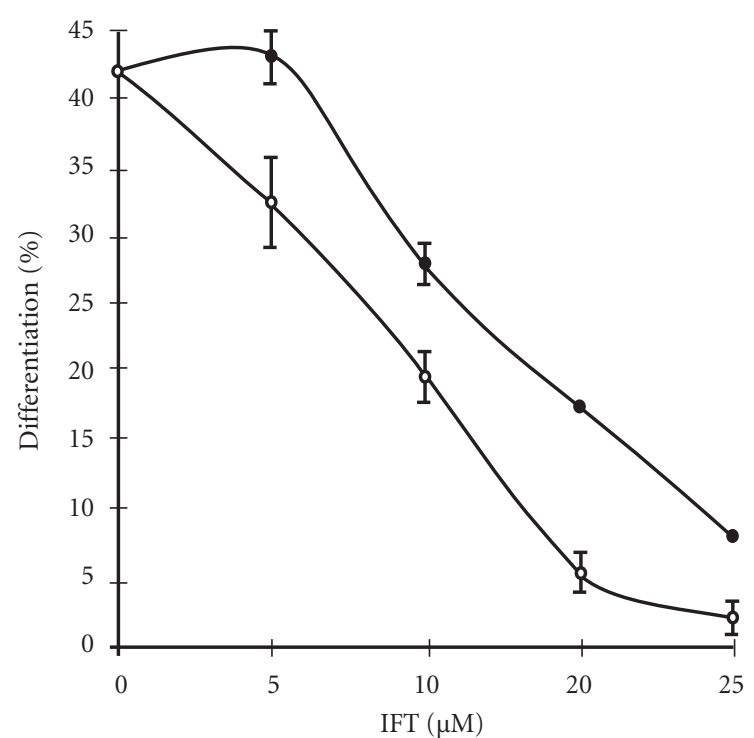

FIGURE 3: Effect of farnesyltransferase inhibitors on differentiation of HL-60 cells by ATRA. HL-60 cells were pretreated with increasing concentrations of FTI-II $(\bullet)$ or FTI-277 (०). After 24 hours, The ATRA $(1 \mu \mathrm{M})$ was added to culture medium. Cell differentiation was determined at day 4 .

\section{Effect of increasing concentrations of low-density lipoprotein on differentiation of $H L-60$ cells by ATRA}

In order to test the cholesterol effect on ATRA-induced cell differentiation, the cells were incubated in the presence of ATRA $(1 \mu \mathrm{M})$ and increasing concentrations of LDL, up to $80 \mu \mathrm{g} / \mathrm{ml}$. Under such conditions, the differentiation of ATRA-treated cells was decreased from $78 \%$ to $54 \% \pm 2.8$. Interestingly, a concomitant decrease of cell growth (48\%) was evidenced in the presence of high concentrations of LDL (Figure 2).

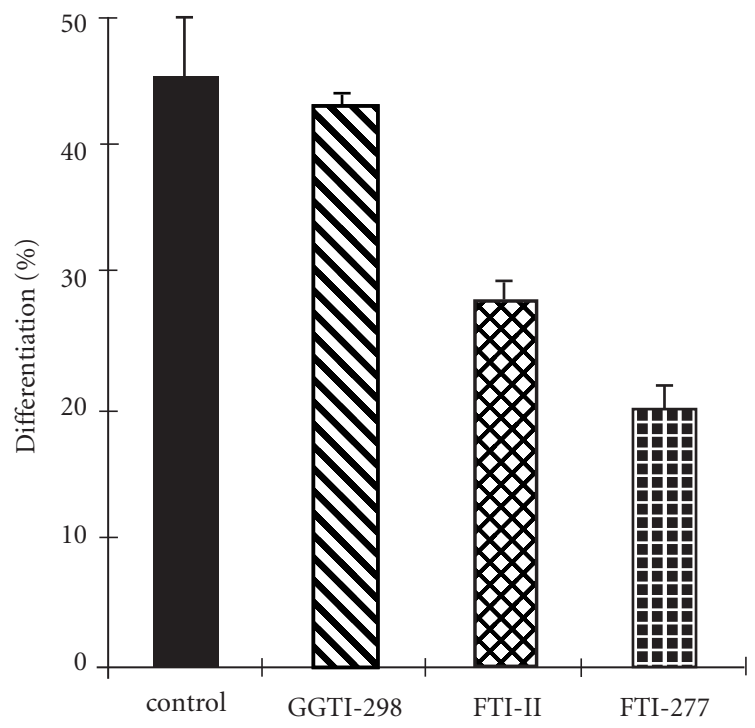

FIGURE 4: Effect of prenylation protein inhibitor on differentiation of HL- 60 cells by ATRA. HL- 60 cells were pretreated with $10 \mu \mathrm{M}$ of GGTI-298 or FTI-II or FTI-277. After 24 hours, The ATRA $(1 \mu \mathrm{M})$ was added to culture medium. Cell differentiation was determined at day 4 .

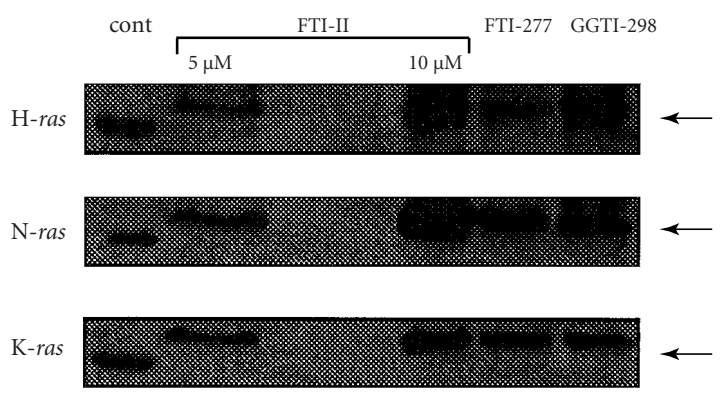

FIGURE 5: Inhibition of $H$-ras, $N$-ras, and $K$-ras prenylation by FTIII, FTI-277, and GGTI-298 HL-60 cells were treated with 5 or $10 \mu \mathrm{M}$ of FTI-II or $10 \mu \mathrm{M}$ of FTI-277 or GGTI-298 for 24 hours. Cell lysates were analyzed by Western blotting with either a $H$-ras monoclonal antibody or a $\mathrm{N}$-ras polyclonal antibody or a $\mathrm{K}$-ras monoclonal antibody. Arrows, unprenylated ras bands.

\section{Evidence for the involvement of prenylated proteins in HL-60 cell differentiation}

The cells were preincubated in the presence of the farsnesyltransferase inhibitor II or farnesyltransferase inhibitor FTI-277 during 24 hours, then treated by ATRA during 3 days (Figure 3). A strong decrease of ATRA-induced differentiation was observed with increasing concentrations of both inhibitors. FTI-277 was a more potent inhibitor compared with FTI-II (Figure 3 ). Indeed, the differentiating activity by ATRA 


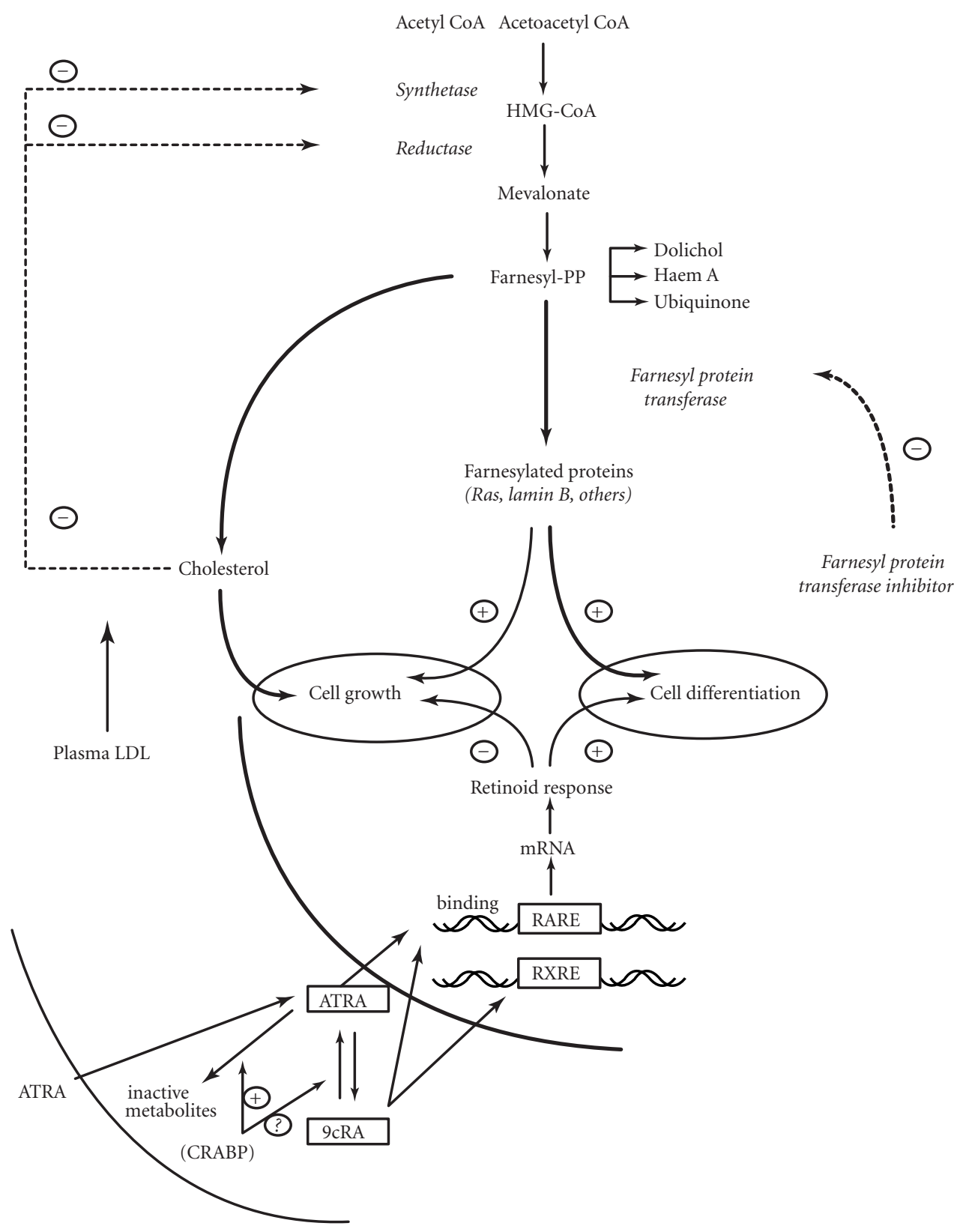

FIGURE 6: Interaction between mevalonate pathway and retinoic acid-induced differentiation.

was totally abolished at $25 \mu \mathrm{M}$ of FTI-277 (Figure 3) and $40 \mu \mathrm{M}$ of FTI-II (data not shown). These results confirmed the involvement of the nonsterol mevalonate pathway in cell differentiation.

When the cells were preincubated in the presence of $10 \mu \mathrm{M}$ of GGTI-298 during 24 hours, then treated by ATRA during 3 days, no significant result was observed compared with control cells whereas, at the same concentration $(10 \mu \mathrm{M})$, FTI-II and FTI-277 decrease ATRA-induced differentiation of the cells (Figure 4). The prenylation of $H$-ras, $\mathrm{K}$-ras, and $\mathrm{N}$-ras in the cells is effectively inhibited under the conditions tested (Figure 5). This result suggested that far- nesylated proteins, such as $H$-ras, $K$-ras, and $N$-ras, could be implied in the mechanism of cell differentiation by ATRA.

\section{DISCUSSION}

At $50 \mathrm{nM}$, ATRA exhibited $34.9 \%$ and $73 \%$ of cell differentiation in control and compactin-treated cells, respectively. A 24 hours treatment of HL-60 cells by compactin, a potent HMG-CoA reductase inhibitor, increased their sensitivity to ATRA. In fact, HMG-CoA reductase is one of the most highly regulated enzymes. Compactin is well known as inducing an overexpression of reductase protein. In cultured cells, com- 
pactin blocks the synthesis of MVA and triggers adaptive reactions that yield a 200-fold increase in reductase protein within a few hours [11]. After removal of compactin, this enzyme becomes active, boosts the mevalonate pathway with concomitant increase of the sterol and nonsterol products [11]. The increase of ATRA differentiating activity in compactintreated cells could be therefore a consequence of an increase in the sterol or nonsterol compounds or both.

A first attempt was made to check the effect of an excess of cholesterol supply. Increasing concentrations of LDL (up to $80 \mu \mathrm{g} / \mathrm{ml}$ ) enhanced growth inhibition and decreased cell differentiation induced by $1 \mu \mathrm{M}$ of ATRA (Figure 3 ). In the two cases, a limit was reached and this could be a consequence of the remaining activity of endogenous mevalonate pathway [11]. HL-60 cells have numerous receptors for LDL which can therefore deliver cholesterol to the cells [32]. The inhibitory effects could be attributed to the decrease of the nonsterol products.

To confirm the effect of nonsterol products, on cell differentiation, HL- 60 cells were preincubated with the prenylation inhibitors. In the presence of FTI-II, FTI-277 specific inhibitors for farnesyltransferase, ATRA differentiating activity can be totally abolished. By contrast, GGTI-298 has no significant effect. Comparison of the results confirm a predominant role for farnesylation (inhibited by FT-277) compared with geranygeranylation (inhibited by GGTI-298). A less specific inhibitor FTI-II, acting on the two types of isoprenoid compounds, has less pronounced effects. Western blots electrophoresis confirms that, at the concentration used, farnesylation and geranygeranylation reactions were actually inhibited.

Farnesyl proteins include Ras proteins that are involved in the transduction of mitogenic signals. In addition, our results show that compounds of the farnesyl proteins family including $\mathrm{H}$-ras, $\mathrm{N}$-ras, and $\mathrm{K}$-ras could be involved in the retinoic acid-induced differentiation of HL-60 cells. Figure 6 shows the regulation of $\mathrm{HMG}-\mathrm{CoA}$ reductase activity and the role of farnesylated proteins on growth and cell differentiation. ATRA is well known to act up on these processes but, in addition, our results show that farnesyl proteins play a key role in the ATRA-induced differentiation of HL- 60 cells. A mechanism, involving RAR and/or RXR retinoic acid receptors, cannot be excluded but requires further investigations.

Taken together, these results (i) suggested the involvement of mevalonate pathway in ATRA differentiating effect on HL60 cells, and (ii) support the use of HMG-CoA reductase inhibitors as potential adjuvant therapeutic agents in differentiating chemotherapy.

\section{ACKNOWLEDGEMENTS}

We are very grateful to Said M. Sebti and Michelle A. Blaskovich (University of South Florida, H. Lee Moffitt Cancer Center \& Research Institute) for providing us with FTI277 and GGTI-298. We thank Fabrice Fleury for excellent technical assistance.

This work was supported by ANVAR.

\section{REFERENCES}

[1] Brockes J. Developmental biology. Reading the retinoid signals (news; comment). Nature. 1990;345:539-766.

[2] Chomienne C, Ballerini P, Balitrand N, et al. All-transretinoic acid in acute promyelocytic leukemias II. In vitro studies: Structure-function relationship. Blood. 1990;76:1710-1717.

[3] Razak K, Allen PD, Kelsey SM, Gutteridge CN, Newland AC. Modulation of CD13 expression during retinoic acid-induced differentiation of HL60 cells. Leuk Res. 1994;18:629-636.

[4] Evans RM. The steroid and thyroid hormone receptor superfamily. Science. 1988;240:889-895.

[5] Yang N, Schule R, Mangelsdorf DJ, Evans RM. Characterization of DNA binding and retinoic acid binding properties of retinoic acid receptor. Proc Natl Acad Sci USA. 1991;88:3559-3563.

[6] Levin AA, Sturzenbecker LJ, Kazmer S, et al. 9-cis retinoic acid stereoisomer binds and activates the nuclear receptor RXR alpha. Nature. 1992;355:359-361.

[7] Heyman RA, Mangelsdorf DJ, Dyck JA, et al. 9-cis retinoic acid is a high affinity ligand for the retinoid X receptor. Cell. 1992;68:397-406.

[8] Breitman TR, Chen ZX, Takahashi N. Potential applications of cytodifferentiation therapy in hematologic malignancies. Semin Hematol. 1994;31:18-25.

[9] Ruchaud S, Duprez E, Gendron MC, et al. Two distinctly regulated events, priming and triggering, during retinoid-induced maturation and resistance of NB4 promyelocytic leukemia cell line. Proc Natl Acad Sci USA. 1994;91:8428-8432.

[10] Drach J, Lopez-Berestein G, McQueen TT, Andreeff $\mathrm{M}$, Mehta K. Induction of differentiation in myeloid leukemia cell lines and acute promyelocytic leukemia cells by liposomal all-trans-retinoic acid. Cancer Res. 1993;53:2100-2104.

[11] Goldstein JL, Brown MS. Regulation of mevalonate pathway. Nature. 1990;343:425-430.

[12] Osborne TF, Gil G, Goldstein JL, Brown MS. Operator constitutive mutation of 3-hydroxy-3-methylglutaryl coenzyme A reductase promoter abolishes protein binding to sterol regulatory element. J Biol Chem. 1988;263:3380-3387.

[13] Osborne TF. Single nucleotide resolution of sterol regulatory region in promoter for 3-hydroxy-3methylglutaryl coenzyme A reductase. J Biol Chem. 1991;266:13947-13951.

[14] Smith JR, Osborne TF, Brown MS, Goldstein JL. Multiple sterol regulatory elements in promoter for hamster 3-hydroxy-3-methylglutaryl-coenzyme A synthase. J Biol Chem. 1988;263:18480-18487.

[15] Trzaskos JM, Magolda RM, Favata MF, et al. Modulation of 3-hydroxy-3-methylglutaryl-CoA reductase by 15 alpha-fluorolanost-7-en-3 beta-ol. A mechanismbased inhibitor of cholesterol biosynthesis. J Biol Chem. 1993;268:22591-22599. 
[16] Correll CC, Edwards PA. Mevalonic acid-dependent of 3-hydroxy-3-methylglutaryl-coenzyme A reductase in vivo and in vitro. J Biol Chem. 1994;269:633-638.

[17] Correll CC, Ng L, Edwards PA. Identification of farnesol as the non-sterol derivative of mevalonic acid required for the accelerated degradation of 3-hydroxy3-methylglutaryl-coenzyme A reductase. J Biol Chem. 1994;269:17390-17393.

[18] Schafer WR, Kim R, Sterne R, Thorner J, Kim SH, Rine J. Genetic and pharmacological suppression of oncogenic mutations in ras genes of yeast and humans. Science. 1989;245:379-385.

[19] Hancock JF, Magee AI, Childs JE, Marshall CJ. All ras proteins are polyisoprenylated but only some are palmitoylated. Cell. 1989;57:1167-1177.

[20] Glomset JA, Gelb MH, Farnsworth CC. Prenyl proteins in eukaryotic cells: a new type of membrane anchor. Trends Biochem Sci. 1990;15:139-142.

[21] Casey PJ, Solsky PA, Der CJ, Buss JE. p21ras is modified by a farnesyl isoprenoid. Proc Natl Acad Sci USA. 1989;86:8323-8327.

[22] Cox AD, Der CJ. The ras/cholesterol connection: implications for ras oncogenicity. Crit Rev Oncog. 1992;3:365400.

[23] Gibbs JB. Ras C-terminal processing enzymes-new drug targets?. Cell. 1991;65:1-4.

[24] Prendergast GC, Davide JP, Desolms SJ, et al. Farnesyltransferase inhibition causes morphological reversion of ras-transformed cells by a complex mechanism that involves regulation of the actin cytoskeleton. Mol Cell Biol. 1994;14:4193-4202.

[25] Glomset JA, Farnsworth CC. Role of protein modification reactions in programming interactions between ras-related GTPases and cell membranes. Annu Rev Cell Biol. 1994;10:181-205.
[26] Casey PJ. Biochemistry of protein prenylation. J Lipid Res. 1992;33:1731-1740.

[27] Grunler J, Ericsson J, Dallner G. Branch-point reactions in the biosynthesis of cholesterol, dolichol, ubiquinone and prenylated proteins. Biochim Biophys Acta. 1994;1212:259-277.

[28] Marshall CJ. Protein prenylation: a mediator of proteinprotein interactions. Science. 1993;259:1865-1866.

[29] Tilbrook PA, Paterson HF, Marshall CJ. Reversion of a human tumour cell line containing oncogenic p21 ras is associated with a defect in the post-translational processing of the ras protein. Oncogene. 1995;10:805-809.

[30] Brousseau T, Clavey V, Bard JM, Fruchard JC. Sequential ultracentrifugation micromethod for separation of serum lipoproteins and assays of lipids, apolipoproteins, and lipoprotein particles. Clin Chem. 1993;39:960-964.

[31] Collins SJ, Ruscetti FW, Gallagher RE, Gallo RC. Normal functional characteristics of cultured human promyelocytic leukemia cells (HL-60) after induction of differentiation by dimethylsulfoxide. J Exp Med. 1979;149:969974.

[32] Gueddari N, Bobichon H, Depierreux C, et al. Enhancement of All-Trans-Retinoic Acid Efficiency in granulocytic differentiation of HL-60 cells by incorporation into low density lipoproteine. Int J Oncol. 1998;13:10691075.

${ }^{*}$ Corresponding author. E-mail: jc.jardi11ier@univ-reims.fr. Fax: +33 326053730 . 

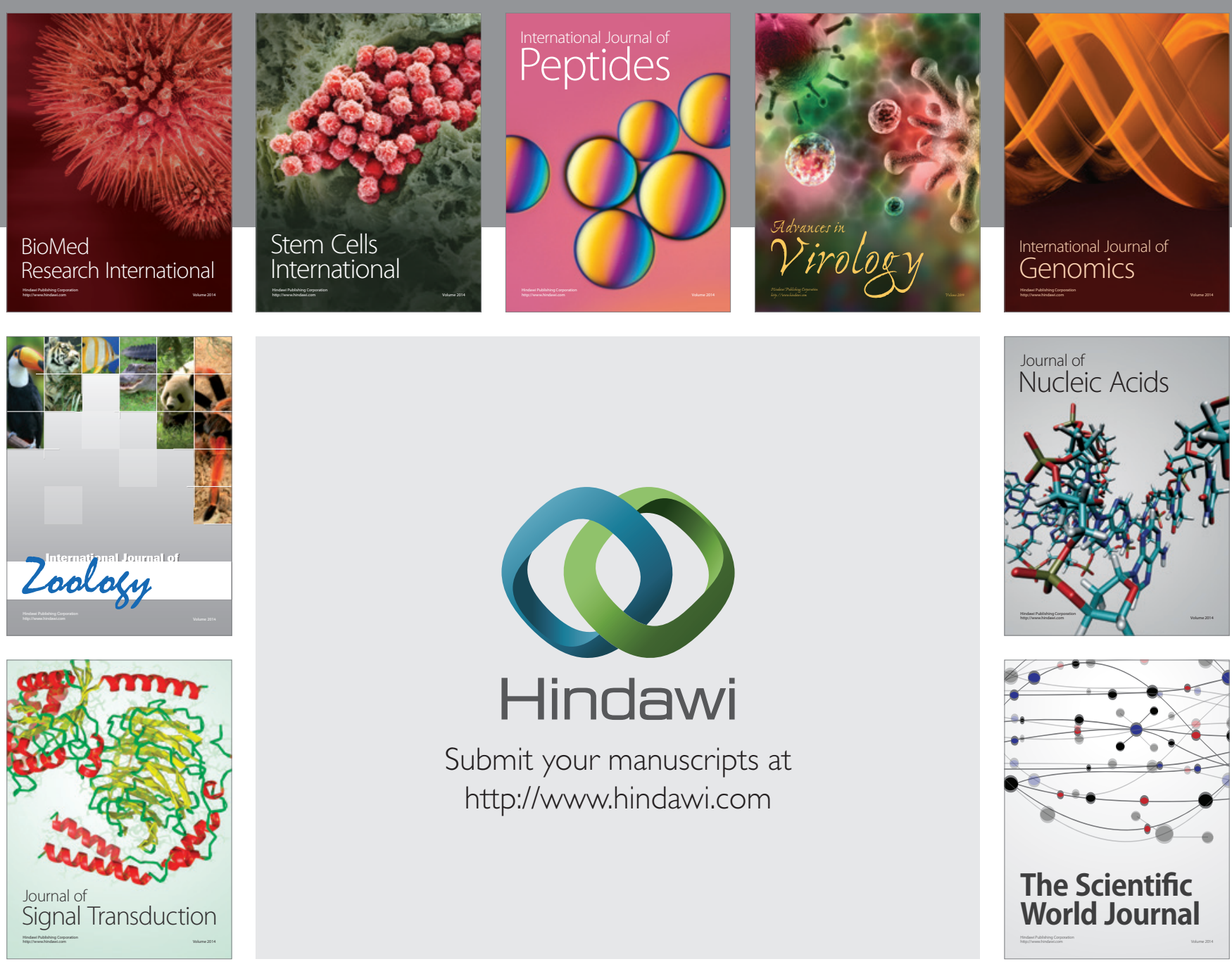

Submit your manuscripts at

http://www.hindawi.com
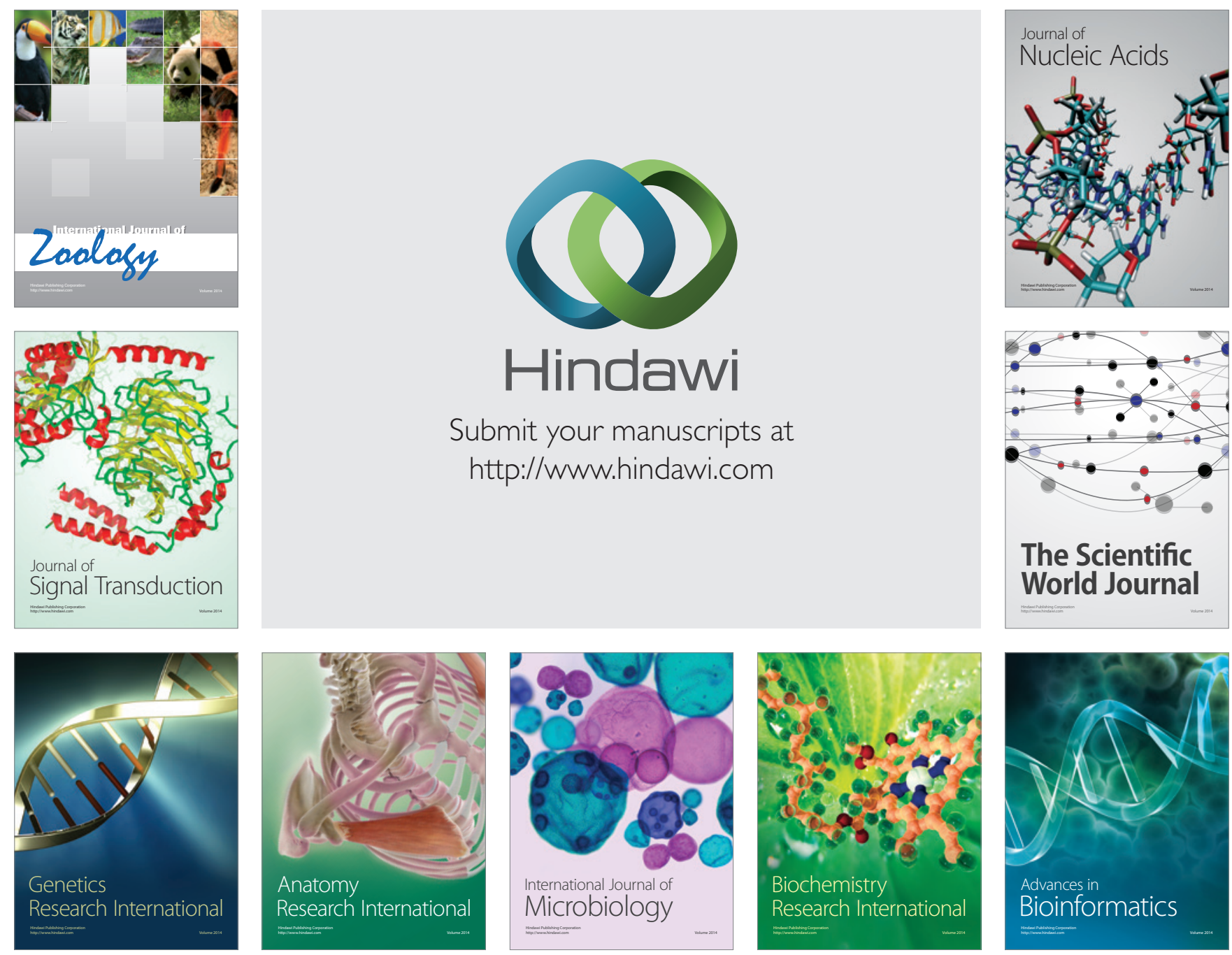

The Scientific World Journal
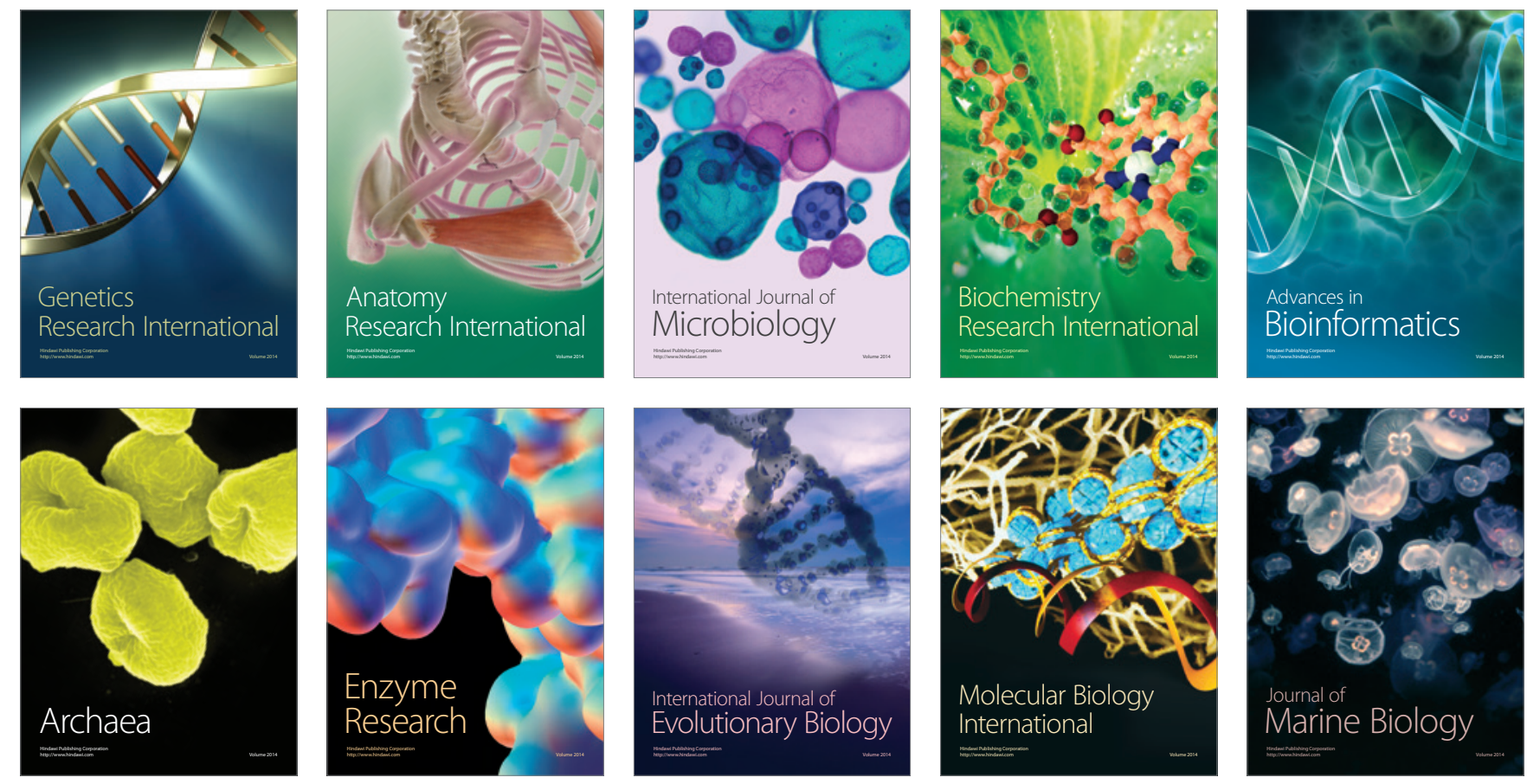